\title{
To Determine the Influence of the Complete Denture Prosthesis on Masticatory Muscle Activity in Elderly Patients: An in vivo Study
}

\author{
Haifa Ashraf \\ Assistant Professor, Department of Prosthodontics, Riyadh College of Dentistry and Pharmacy, Saudi Arabia
}

Correspondence: Haifa Ashraf, Assistant Professor, Department of Prosthodontics, Riyadh College of Dentistry and Pharmacy Saudi Arabia, e-mail: aifa_abs@yahoo.in

\section{ABSTRACT}

Introduction: Mastication is a highly coordinated neuromuscular function involving fast effective movements of the jaw and continuous modulation of force. In older subjects these mechanisms act with marked differences. They have a reduced capacity in various functions of stomatognathic system.

Objectives: To evaluate the elevator and depressor muscle activity with and without complete denture prosthesis.

Materials and methods: For the purpose of the study 12 patients between the age of 40 and 70 years were selected. Surface electrodes from the electromyographic unit were placed in the region of right and left anterior temporal muscles, Masseter muscle and depressor muscle at the region of anterior belly of digastric and the electromyographic activity was recorded.

Results and discussion: The obtained values were subjected to statistical analysis. A paired t- test was performed to determine the difference between the subjects with and without denture prosthesis.

Conclusion: The elevator muscles showed higher activity in subjects wearing the denture prosthesis when compared to those without denture prosthesis. No significant change in muscle activity was seen on maximal opening of the depressor muscle between the subjects with and without denture prosthesis.

Keywords: Maximal voluntary contraction, Electromyography, Masticatory muscles.

\section{INTRODUCTION}

The masticatory system is the functional unit composed of the teeth, their supporting structures, the jaws, the temporomandibular joints, the associated muscles, and vascular and nervous systems for these tissues.

Mastication is a highly coordinated neuromuscular function involving fast effective movements of the jaw and continuous modulation of force. ${ }^{1}$

It is an alternating rhythm of isotonic and isometric contractions governed by a central pattern generator located in the brainstem. ${ }^{2}$ It is characterized by rhythmicity and a diversity of patterns of jaw, tongue and facial movements that vary depending on the species and food ingested. ${ }^{3}$

Masticatory function is generated by rhythmic contraction of the masticatory muscles. These muscles have the capacity to contract during daily use of the stomatognathic system and maintain muscle tone in mandibular rest position.

In older subjects these mechanisms act with marked differences. They have a reduced capacity in various functions of stomatognathic system. Some age related changes, such as deterioration in the fast and slow-twitch fibers of the striated muscles, result in impaired muscle force.

Chewing efficiency is reduced when teeth are replaced by complete dentures. The loss of teeth and elimination of periodontal afferent flow lead to changes in the neuromuscular patterns. Edentulous persons have reduced capacity in various functions of the stomatognathic system, such as occlusal force, tactile thresholds and chewing ability. ${ }^{2}$

Although various techniques are available for examining, the stomatognathic system recording of electromyographic activity is a convenient and useful method because it directly measures muscle activity. Electromyographic techniques have permitted more precise assessment of the muscle functions than that was previously possible by clinical observation.

Several studies have been done to investigate the activity of the elevator muscle while depressor activity during chewing has not been completely studied. The objective of the study is to show that elevator and depressor muscle activity during mastication is altered by the presence of complete denture prosthesis.

\section{MATERIALS AND METHODS}

A total of 12 subjects between the age group of 40 and 70 years visiting the Outpatient Department of $\mathrm{AB}$ Shetty Memorial Institute of Dental Sciences, Deralakatte, Mangalore, were included in the study. The study was carried out in Department of Neurology, KS Hegde Medical Academy, Deralakatte, Mangalore. 


\section{Criteria for Selection of Subjects}

Complete denture patients included in the study had:

1. A prosthesis with satisfactory interocclusal and maxillomandibular relationship

2. Adequate masticatory efficiency

3. Oral mucosa free of irritation and clinical signs of inflammation

4. No history of mandibular dysfunction or any disease that affect the muscles of masticatory system.

All subjects gave informed consent. The study was approved by the ethical committee of AB Shetty Memorial Institute of Dental Sciences, Deralakatte, Mangalore.

\section{EMG RECORDING PROCEDURE}

Surface EMG recordings were obtained from the left and right anterior temporal muscles, the left and right masseter muscles and submandibular group of muscles on the left and right sides in the region of anterior belly of digastric muscle. The electrodes were fixed with double-sided adhesive tapes. A plate ground electrode was secured to the forehead.

The skin was cleaned with $99.5 \%$ alcohol swabs and a skinpreparation gel. A conductive gel was applied between the electrode and the skin to reduce the impedance below $20 \mathrm{kV}$. Recordings were performed 5 minutes later, which allowed the conductive paste to adequately moisten the surface. The EMG signals were filtered (0.003-1.0 kHz) and amplified with a time constant of 10 minutes, and displayed on cathode-ray tube (CRT) monitor for the online monitoring.

\section{Procedure}

\section{EMG Recording of Temporalis Muscle}

Two pairs of miniature surface $\mathrm{Ag} / \mathrm{AgCl}$ electrodes were placed over the temporal muscle 1 inch posterior and 1inch superior to the outer canthus of the eye. The ground electrodes were placed over the skin of the sternocleidomastoid muscle. The EMG activity recording for the right and left temporalis muscle is recorded at maximum intercuspal position in subjects with complete denture prosthesis.

Edentulous subjects were asked to clench with their edentulous ridges in contact and maximal activity of the elevator muscle was established. The subjects clenched manually for 5 seconds and rested for 15 seconds and repeated the clenching cycle five times. The highest EMG activity was considered the maximum clenching EMG activity during a given period.

\section{EMG Recording of Masseter Muscle}

Electrodes over the masseter muscle were placed $2 \mathrm{~cm}$ above the lower margin of the mandible, halfway between the mandibular angle and anterior border of the muscle were identified by palpation and the same procedure as mentioned above was followed to record EMG activity of the right and left masseter muscles.

\section{EMG Recording of Submandibular Group of Muscles}

Electrode were placed along the anterior belly of digastric muscle in the suprahyoid triangle and subjects were made to perform maximal wide opening with and without dentures and the EMG activity of the submandibular group of muscles at the region of anterior belly of digastric were recorded.

\section{RESULTS}

The data of the study were analyzed and the results are presented in the table I-VI. These tables present the mean values of the electromyographic activity of masseter and temporalis muscle with and without dentures during maximum voluntary contraction (MVC) in the intercuspal position.

Statistical analysis reveals that during maximal voluntary contraction, the temporalis muscle of each side with prosthesis showed mean activity of $417.66 \mu \mathrm{V}$ (RT side $418.08 \mu \mathrm{V}$ and LT side $417.25 \mu \mathrm{V}$ ) when compared to $342.25 \mu \mathrm{V}$ ( RT side $343.25 \mu \mathrm{V}$ and LT side $341.25 \mu \mathrm{V}$ ) in subjects without complete denture prosthesis (Table 1).

Statistical analysis reveals a highly significant increase in the temporalis muscle activity ( $=0.003 \& \mathrm{p}=0.002)$ with complete denture when compared to subjects without complete denture prosthesis during maximum voluntary contraction (Table 2).

Statistical data reveals that during maximal voluntary contraction the masseter muscle of each side with denture showed mean activity of $432.75 \mu \mathrm{V}$ (RT side $435.55 \mu \mathrm{V}$ and LT side $430.17 \mu \mathrm{V}$ ) when compared to $320.29 \mu \mathrm{V}$ (RT side $322.92 \mu \mathrm{V}$ and LT side $317.67 \mu \mathrm{V}$ ) subjects without complete denture prosthesis (Table 3).

Statistical analysis reveals a highly significant increase in the masseter muscle activity $(p=0.001 \& p=0.001)$ with denture than subjects without dentures during maximum voluntary contraction (Table 4).

This data reveals that during maximal opening position the depressor muscle of each side showed mean activity of $491.55 \mu \mathrm{V}$ (RT side $491.92 \mu \mathrm{V}$ and $491.17 \mu \mathrm{V}$ ) with denture when compared to $496.34 \mu \mathrm{V}$ in subjects without complete denture prosthesis (Table 5).

Statistical analysis of these data did not show any significant difference in muscle activity ( $=0.881 \& \mathrm{p}=0.883$ ) on comparison between with and without denture at maximal opening (Table 6).

\section{DISCUSSION}

The masticatory system is the functional unit of the body primarily responsible for chewing, speaking and swallowing. The system is made up of bones, joints, ligaments, teeth and muscles, and an intricate neurologic controlling system regulates and coordinates all these structural components.

Masticatory function is generated by rhythmic contraction of the masticatory system. Several other parameters are important, such as number of teeth and quality of occlusal contacts and health of the masticatory system. ${ }^{4}$ 
To Determine the Influence of the Complete Denture Prosthesis on Masticatory Muscle Activity in Elderly Patients

\begin{tabular}{|c|c|c|c|c|c|}
\hline \multicolumn{6}{|c|}{ Paired samples statistics } \\
\hline & & Mean & $N$ & Std. deviation & $\begin{array}{l}\text { Std. error } \\
\text { mean }\end{array}$ \\
\hline \multirow[t]{2}{*}{ Pair 1} & Right side with denture & 418.08 & 12 & 161.93 & 46.75 \\
\hline & Right side without denture & 343.25 & 12 & 146.56 & 42.31 \\
\hline \multirow[t]{2}{*}{ Pair 2} & Left side with denture & 417.25 & 12 & 160.33 & 46.28 \\
\hline & Left side without denture & 341.25 & 12 & 147.59 & 42.61 \\
\hline
\end{tabular}

Table 2: Statistical analysis to compare the activity of temporalis muscle in subjects with and without dentures during maximum voluntary contraction

\begin{tabular}{|c|c|c|c|c|c|c|c|c|c|}
\hline \multicolumn{10}{|c|}{$\begin{array}{l}\text { Paired samples test } \\
\text { Paired differences }\end{array}$} \\
\hline & & \multirow[t]{2}{*}{ Mean } & \multirow[t]{2}{*}{$\begin{array}{l}\text { Std. } \\
\text { deviation }\end{array}$} & \multirow[t]{2}{*}{$\begin{array}{l}\text { Std. } \\
\text { error } \\
\text { mean }\end{array}$} & \multicolumn{2}{|c|}{$\begin{array}{l}95 \% \text { confidence } \\
\text { interval of the } \\
\text { difference }\end{array}$} & \multirow[t]{2}{*}{$t$} & \multirow[t]{2}{*}{$d f$} & \multirow[t]{2}{*}{ p-value } \\
\hline & & & & & Lower & $\overline{\text { Upper }}$ & & & \\
\hline Pairl 1 & $\begin{array}{l}\text { Right side with denture } \\
\text { Right side without denture }\end{array}$ & 74.83 & 67.75 & 19.56 & 31.79 & 117.88 & 3.826 & 11 & 0.003 \\
\hline Pair 2 & $\begin{array}{l}\text { Left side with denture } \\
\text { Left side without denture }\end{array}$ & 76.00 & 66.04 & 19.06 & 34.04 & 117.96 & 3.986 & 11 & 0.002 \\
\hline
\end{tabular}

Table 3: Comparison between the activity of masseter muscle in subjects with and without dentures during maximum voluntary contraction

\begin{tabular}{|c|c|c|c|c|c|}
\hline \multicolumn{6}{|c|}{ Paired samples statistics } \\
\hline & & Mean & $N$ & Std. deviation & $\begin{array}{l}\text { Std. error } \\
\text { mean }\end{array}$ \\
\hline \multirow[t]{2}{*}{ Pair 1} & Right side with denture & 435.33 & 12 & 150.21 & 43.36 \\
\hline & Right side without denture & 322.92 & 12 & 115.65 & 33.39 \\
\hline \multirow[t]{2}{*}{ Pair 2} & Left side with denture & 430.17 & 12 & 149.93 & 43.28 \\
\hline & Left side without denture & 317.67 & 12 & 116.20 & 33.55 \\
\hline
\end{tabular}

Table 4: Statistical analysis showing comparison between the activity of masseter muscle in subjects with and without dentures during maximum voluntary contraction.

\begin{tabular}{|c|c|c|c|c|c|c|c|c|c|}
\hline \multicolumn{10}{|c|}{$\begin{array}{l}\text { Paired samples test } \\
\text { Paired differences }\end{array}$} \\
\hline & & \multirow[t]{2}{*}{ Mean } & \multirow[t]{2}{*}{$\begin{array}{l}\text { Std. } \\
\text { deviation }\end{array}$} & \multirow[t]{2}{*}{$\begin{array}{l}\text { Std. } \\
\text { error } \\
\text { mean }\end{array}$} & \multicolumn{2}{|c|}{$\begin{array}{l}\text { 95\% confidence } \\
\text { interval of the } \\
\text { difference }\end{array}$} & \multirow[t]{2}{*}{$t$} & \multirow[t]{2}{*}{$d f$} & \multirow[t]{2}{*}{ p-value } \\
\hline & & & & & Lower & Upper & & & \\
\hline Pairl 1 & $\begin{array}{l}\text { Right side with denture } \\
\text { Right side without denture }\end{array}$ & 112.4 & 84.33 & 24.34 & 58.84 & 165.99 & 4.62 & 11 & 0.001 \\
\hline Pair 2 & $\begin{array}{l}\text { Left side with denture } \\
\text { Left side without denture }\end{array}$ & 112.5 & 85.66 & 24.73 & 58.07 & 166.93 & 4.55 & 11 & 0.001 \\
\hline
\end{tabular}

To understand the underlying neurologic process of muscle hyperactivity, electromyography (EMG) has been widely used. $^{5}$

Electromyography, a sensitive tool, overcomes the difficulty encountered to analyze and quantify the behavior of the masticatory muscles. It has been widely used for measuring muscle function since first introduced by RE Moyers in 1949.

EMG is the recording of action potential from motor units. The EMG from weak contractions consists of action potential from a single or a few motor units contractions with a low 
Table 5: Comparison between the activity of depressor muscle in subjects with and without dentures at maximal opening

\begin{tabular}{lllcll}
\hline \multicolumn{3}{c}{ Paired samples statistics } \\
\hline & Mean & $N$ & Std. deviation & $\begin{array}{l}\text { Std. error } \\
\text { mean }\end{array}$ \\
\hline \multirow{2}{*}{ Pair 1} & & & & 47.98 \\
& Right side with denture & 491.92 & 12 & 166.22 & 39.85 \\
\multirow{2}{*}{ Pair 2} & Right side without denture & 496.75 & 12 & 138.04 & 48.23 \\
& Left side with denture & 491.17 & 12 & 167.08 & 39.03 \\
\hline
\end{tabular}

Table 6: Statistical analysis to compare the activity of depressor muscle in subjects with and without dentures at maximal opening

\begin{tabular}{|c|c|c|c|c|c|c|c|c|c|}
\hline \multicolumn{10}{|c|}{$\begin{array}{l}\text { Paired samples test } \\
\text { Paired differences }\end{array}$} \\
\hline & & \multirow[t]{2}{*}{ Mean } & \multirow[t]{2}{*}{$\begin{array}{l}\text { Std. } \\
\text { deviation }\end{array}$} & \multirow[t]{2}{*}{$\begin{array}{l}\text { Std. } \\
\text { error } \\
\text { mean }\end{array}$} & \multicolumn{2}{|c|}{$\begin{array}{l}95 \% \text { confidence } \\
\text { interval of the } \\
\text { difference }\end{array}$} & \multirow[t]{2}{*}{$t$} & \multirow[t]{2}{*}{$d f$} & \multirow[t]{2}{*}{ p-value } \\
\hline & & & & & Lower & Upper & & & \\
\hline Pairl 1 & $\begin{array}{l}\text { Right side with denture } \\
\text { Right side without denture }\end{array}$ & -4.83 & 109.65 & 31.65 & -74.50 & 64.84 & -0.153 & 11 & 0.881 \\
\hline Pair 2 & $\begin{array}{l}\text { Left side with denture } \\
\text { Left side without denture }\end{array}$ & -4.75 & 109.32 & 31.56 & -74.21 & 64.71 & -0.151 & 11 & 0.883 \\
\hline
\end{tabular}

frequency. The strength of contraction is increased by more frequent activation of the motor units and by the recruitment of new units. Therefore, in strong contractions the action potential interferes and summates to potential changes with increasing amplitude.

Edentulous persons have reduced capacity in carious functions of the stomatognathic system, such as bite force and chewing efficiency. Several studies have shown that denture wearers are unable to produce levels of muscle activity at maxillary voluntary contraction comparable to those in subjects with natural teeth due to the change in the influence of peripheral and central neural mechanisms. ${ }^{2}$

Masticatory performances decrease with age as other motion activities. Muscle fatigue accompanied by bite force diminution and tongue-motor decline are often found in elderly persons. These changes that occur during healthy aging depress the masticatory ability and may provoke swallowing difficulties. $^{6}$

Specificities of mastication in complete denture wearers are caused by specificities connected to changes of the oral cavity due to teeth loss, technical features of complete dentures and quality of their manufacture. Loss of teeth causes loss of periodontal receptors consequently damaging the source of information which, as long as teeth are present, travels from the oral cavity towards the central nervous system and regulates the masticatory muscles activity.

Masticatory forces in completely edentulous mouth directly depends on the size of muscles creating the forces, their position in the mandible, type of chewing, shape of the edentulous alveolar ridge and the degree of intermaxillary separation.
Bite forces in complete denture wearers are significantly decreased in relation to people with natural teeth. There is a fundamental difference in the distribution of the functional energy in complete denture wearers and subjects with intact teeth. Reduction of masticatory efficacy in denture wearers may be caused by irregular activity of masticatory musculature or is the consequence of irregular flow of energy during mastication. ${ }^{7}$

In a previous study by Miralles $\mathrm{R}$ et $\mathrm{al}^{8}$ showed that the integrated EMG activity of both muscles during maximal voluntary clenching was significantly lower in patients with complete dentures than in subjects with natural dentition. During saliva swallowing the activity in both muscles was similar in both groups. This may have a great clinical significance in the maintenance of the functional state of the different structures of the stomatognathic system in complete denture wearers.

This study reveals that maximum elevator activity levels in maximum voluntary contraction were higher in subjects with denture prosthesis than edentulous subjects while during maximal opening depressor muscle activity levels were similar in these groups.

Numerous studies have compared the muscle activity in complete denture wearers with superior and poor masticatory performance and showed that new dentures or improvements in occlusion vertical dimension and stability of poorly fitting dentures produce better chewing efficiency and masticatory performance. ${ }^{9}$

Several authors have investigated the relationship between the masticatory performance and subjects own assessments of their chewing ability, denture quality and oral conditions. 
Millers et al showed that low muscle activity in patients with complete denture might be a consequence of a change in the influence of peripheral or central neural mechanisms, since in edentulous patients the periodontal receptors are missing, and mucosal mechanoreceptors play a main role in replacing them. Change in input from peripheral receptors and their influence on trigeminal motor neuron pools could be expected with loss of natural teeth. ${ }^{2}$

In a previous study of elevator muscle activity in patients before and after complete dentures suggest that the use of complete denture provokes electromyographic changes by increasing the occlusal vertical dimension. ${ }^{6}$

Although numerous studies have described the comparison of different parameters in edentulous subjects and natural dentition little comparative information has been shown regarding the complete denture patients.

The data of this study showed a significant increase in the electromyographic activity of temporalis muscle in subjects with denture prosthesis at $417.66 \mu \mathrm{V}$ (RT side $418.08 \mu \mathrm{V}$ and LT side $417.25 \mu \mathrm{V}$ ) when compared to $342.25 \mu \mathrm{V}$ (RT side $343.25 \mu \mathrm{V}$ and $\mathrm{LT}$ side $341.25 \mu \mathrm{V}$ ) in subjects without dentures. $(\mathrm{p}=0.003 \& \mathrm{p}=0.002)$

A significant increase was also seen in the electromyographic activity of the masseter muscle in subjects with denture prosthesis; $432.75 \mu \mathrm{V}$ (RT side $435.55 \mu \mathrm{V}$ and LT side $430.17 \mu \mathrm{V}$ ) when compared to $320.29 \mu \mathrm{V}$ (RT side $322.92 \mu \mathrm{V}$ and $317.67 \mu \mathrm{V})$ in subjects without prosthesis. $(\mathrm{p}=0.001)$.

A study by Verkindere et $\mathrm{al}^{10}$ showed that the electrical activity of temporal muscles were slightly affected by the absence and replacement of teeth, whereas the electrical activity of the masseter muscles was markedly altered.

A previous study by Raustia et $\mathrm{al}^{11}$ suggested that a long edentulous period is visible not only in the functioning of the masticatory muscles, in terms of decreased EMG activity, but also as decreased density of the muscles which implies muscle atrophy, as seen by computed tomography in the masticatory muscles.

Although some studies have been concerned with depressor muscle EMG activity, their results have considered only subjects with natural teeth, and the results cannot be applied to the complete dentures. ${ }^{2}$

The data of this study does not show any significant difference in the depressor muscle activity between subjects with and without denture prosthesis.

This study reveals that during maximal opening, the depressor muscle showed a mean activity of $491.55 \mu \mathrm{V}$ (RT side $491.92 \mu \mathrm{V}$ and $491.17 \mu \mathrm{V}$ ) in subjects with denture when compared to $496.34 \mu \mathrm{V}$ in subjects without prosthesis $(\mathrm{p}>0.05)$.

The above-mentioned observations indicate that the subjects without denture show decreased elevator muscle activity during maximum voluntary contraction when compared to subjects with dentures. No difference in the activity of the depressor muscle was seen on maximal opening in subjects with and without denture prosthesis.

\section{SUMMARY AND CONCLUSION}

Mastication being a complex biologic function utilizing various components, such as muscles, dentition and neural control; requires these various controlling components to be in harmony and optimal health. When one of these components loses their function the masticatory efficiency of the individual is hampered. The restoring of the lost or affected component may, to some extent, bring back the patients masticatory efficiency. This study was conducted to determine the influence of complete denture prosthesis on the masticatory muscle activity in elderly patients who had lost their entire compliment of teeth.

For the purpose of the study, 12 patients between the age of 40 and 70 years were selected as subjects for the investigation.

Surface electrodes from the electromyographic unit were placed in the region of right and left anterior temporal muscles, masseter muscle and depressor muscle at the region of anterior belly of digastric and the patients were asked to perform maximal voluntary contraction and maximal opening. The electromyographic activity was recorded for the various groups of muscles on both the left and right side. The data of the study analyzed and the results have been presented in the Tables 1 to 6 .

The elevator muscles showed higher activity in subjects wearing the denture prosthesis when compared to those without denture prosthesis. No significant change in muscle activity was seen on maximal opening of the depressor muscle between the subjects with and without denture prosthesis.

\section{REFERENCES}

1. Karkazis HC, Kossioni AE. Surface EMG activity of the masseter muscle in denture wearers during chewing of hard and soft food. J Oral Rehabil 1998;25:8-14.

2. Alajberg Iva Z, Valentic-Peruzovic Melita. The influence of dental status on masticatory muscle activity in elderly patients. Int J Prosthodont 2005;18:333-38.

3. Tzakis Mihail G, Karlsson Stig, Carlsson Gunnar E. Effects of intense chewing on some parameters of masticatory function. J Prosthet Dent 1992;67:405-09.

4. Markoviæ D, Petrović L, Primović. Specifics of mastication with complete dentures Med Pregl Nov-Dec 1999;52(11-12):464-68.

5. Tallgren A, Lang BR, Holden S, Miller RL. Longitudinal electromyographic study of swallowing patterns in complete denture wearers. Int J Prosthodont Sep-Oct 1995;8(5):467-78.

6. Liu ZJ, Yamagata K, Kasahara Y, Ito G. Electromyographic examination of jaw muscles in relation to symptoms and occlusion of patients with temporomandibular joint disorders. Journal of Oral Rehabilitation 1999;26:33-47.

7. Piancino MG, Farina D, Talpone F, Castroflorio T, Gassino G, Margarino V, Bracco P. Surface EMG of jaw-elevator muscles and chewing pattern in complete denture wearers. Oral Rehabil Dec 2005;32(12):863-70.

8. Verkindere M, Lodter JP, Alzieu X. Electromyographic study of mastication as a function of the denture in humans. J Biol Buccale Sep 1988;16(3):169-78. 
9. Garrett Neal R, Perez Paul, Elbert Charles, Kapur Krishan K. Effects of improvements of poorly fitting dentures and new dentures on masseter muscle activity during chewing. J Prosthet Dent 1996;76:394-402.

10. Nuño Licona A, Angeles Medina F, Pacheco Segura ME, Sarabia Villa A, García Moreira C. Electromyographic activity (EMG) of masseter and temporal muscles in edentulous patients before and after complete dentures. Pract Odontol Aug 1990;11(8): 54-56.

11. Shi CS, Ouyang G, Guo TW. A comparative study of mastication between complete denture wearers and dentate subjects. J Prosthet Dent Oct 1991; 66(4):505-09. 